\title{
A Conforming Triangular Plane Element with Rotational Degrees of Freedom
}

\author{
Xiang-Rong Fu, ${ }^{1}$ Ming-Wu Yuan, ${ }^{2}$ and Chen $\mathrm{Pu}^{2}$ \\ ${ }^{1}$ Department of Civil Engineering, China Agricultural University, Beijing 100083, China \\ ${ }^{2}$ Department of Mechanics and Engineering Science, Peking University, Beijing 100871, China \\ Correspondence should be addressed to Xiang-Rong Fu; fuxr@cau.edu.cn
}

Received 19 September 2014; Accepted 18 December 2014

Academic Editor: Chenfeng Li

Copyright (c) 2015 Xiang-Rong Fu et al. This is an open access article distributed under the Creative Commons Attribution License, which permits unrestricted use, distribution, and reproduction in any medium, provided the original work is properly cited.

\begin{abstract}
This paper presents a novel way to formulate the triangular plane element with rotational degrees of freedom (RDOF). The linear distribution of rotational displacement is assumed. The conforming displacement along the sides based on the rotational displacement assumption is derived, and the triangular plane element TR3 for isotropic material is formulated. By using the explicit integral formulae of the triangular element, the matrices used in the proposed plane element TR3 are calculated efficiently. The benchmark examples showed thier high accuracy and high efficiency.
\end{abstract}

\section{Introduction}

The triangular plane element is widely used [1-3]. In order to improve the performance of the triangular plane element, rotational degrees of freedom (RDOF) has been introduced. The other advantage of plane elements with RDOF is that the singularity of global stiffness can be avoided in the analysis of shell structures. Mervyn and Terrence introduced the RDOF to describe the displacement of the flat shell element [4]. Mohr constructed the hybrid membrane element with RDOF [5]. Allman et al. presented some rational displacement-type plane elements with RDOF [6-10]. Many researchers improve accuracy of the membrane element by this way [11-15], and the plane elements with RDOF have been widely used in analysis of shell structure.

Long et al. studied the generalized conforming plane elements [16-20] with RDOF. Taking advantage of the conforming boundary displacement, the nonconforming displacement model can be involved freely by the generalized conforming equations [17-20]. Chen et al. proved that the hybrid element using the balanced stress fields can play the same role in the element formulation as the generalized conforming element introducing the associated generalized conforming equations [20]. On the other hand, the hybrid element employed analytical trial functions of stress needs conforming boundary displacement [21-26].

This paper studies the triangular plane element based on the rational assumption of the rotation displacement field. There are mainly four steps as follows in Section 2.

(a) The first step assumes the rational distribution of the rotational displacement (in Section 2.1).

(b) The second step gives the displacement field based on the assumed rotational displacement (in Section 2.2).

(c) The third step formulates the stiffness matrix of the element TR3 based on the associated strain fields (in Section 2.3).

(d) The fourth step calculates the stiffness matrix using the explicit integral formulae of the triangular element (in Section 2.4).

In Section 3, some numerical examples are shown as benchmark to study the accuracy and the efficiency of the proposed element model TR3.

In Section 4, some conclusions are given. 


\section{The Formulation of the Triangular Element TR3 with RDOF}

2.1. The Rational Distribution of the Rotational Displacement. The rotational displacement field in the triangular element with three nodes can be assumed as follows:

$$
\theta_{z}=L_{1} \theta_{Z 1}+L_{2} \theta_{Z 2}+L_{3} \theta_{Z 3},
$$

where

$$
\begin{aligned}
& L_{1}=\frac{\left(a_{1}+b_{1} x+c_{1} y\right)}{2 A}, \\
& L_{2}=\frac{\left(a_{2}+b_{2} x+c_{2} y\right)}{2 A}, \\
& L_{3}=\frac{\left(a_{3}+b_{3} x+c_{3} y\right)}{2 A},
\end{aligned}
$$

where

$$
\begin{gathered}
a_{1}=x_{2} y_{3}-x_{3} y_{2}, \quad a_{2}=x_{3} y_{1}-x_{1} y_{3}, \\
a_{3}=x_{1} y_{2}-x_{2} y_{1}, \\
b_{1}=y_{2}-y_{3}, \quad b_{2}=y_{3}-y_{1}, \\
b_{3}=y_{1}-y_{2}, \\
c_{1}=x_{3}-x_{2}, \quad c_{2}=x_{1}-x_{3}, \\
c_{3}=x_{2}-x_{1}, \\
2 A=x_{1} y_{2}-x_{2} y_{1}-x_{1} y_{3}+x_{3} y_{1}+x_{2} y_{3}-x_{3} y_{2},
\end{gathered}
$$

in which $x_{1}, x_{2}$, and $x_{3}$ and $y_{1}, y_{2}$, and $y_{3}$ are coordinates of three nodes in the triangular element. $\theta_{Z 1}, \theta_{Z 2}$, and $\theta_{Z 3}$ are rotational displacement of three nodes.

2.2. The Distribution of the Displacement. According to the definition of the rotation displacement in the elasticity, the relationship between displacement symbols $u, v$ and the rotational displacement $\theta_{Z}$ can be denoted as

$$
\theta_{z}=\frac{1}{2}\left(\frac{\partial u}{\partial y}-\frac{\partial v}{\partial x}\right)
$$

From (1),

$$
\begin{aligned}
\theta_{z}= & \left(a_{1} \theta_{z 1}+a_{2} \theta_{z 2}+a_{3} \theta_{z 3}\right)+\left(b_{1} \theta_{z 1}+b_{2} \theta_{z 2}+b_{3} \theta_{z 3}\right) x \\
& +\left(c_{1} \theta_{z 1}+c_{2} \theta_{z 2}+c_{3} \theta_{z 3}\right) y \\
= & A_{z}+B_{z} x+C_{z} y .
\end{aligned}
$$

From (4) and (5), we can assume

$$
\begin{aligned}
& u(x, y)=\frac{A_{z}}{2}+\frac{B_{z} x y}{2}+\frac{C_{z}}{4} y^{2}+f_{u}(x, y), \\
& v(x, y)=-\frac{A_{z}}{2}-\frac{B_{z}}{4} x^{2}-\frac{C_{z} x y}{2}+f_{v}(x, y),
\end{aligned}
$$

where we can give two assumptions,

$$
\begin{aligned}
& f_{u}(x, y)=u_{0}+u_{x} x+u_{y} y, \\
& f_{v}(x, y)=v_{0}+v_{x} x+v_{y} y .
\end{aligned}
$$

On the other hand, we can define the displacement fields in the triangular element as

$$
\begin{aligned}
& u=g_{u}\left(u_{1}, u_{2}, u_{3}, \theta_{Z 1}, \theta_{Z 2}, \theta_{Z 3}, x, y\right), \\
& v=g_{v}\left(v_{1}, v_{2}, v_{3}, \theta_{Z 1}, \theta_{Z 2}, \theta_{Z 3}, x, y\right) .
\end{aligned}
$$

According to (6)-(8), the nodal conforming requirement can be given as

$$
\begin{array}{lll}
u_{1}=u\left(x_{1}, y_{1}\right), & u_{2}=u\left(x_{2}, y_{2}\right), & u_{3}=u\left(x_{3}, y_{3}\right), \\
v_{1}=v\left(x_{1}, y_{1}\right), & v_{2}=v\left(x_{2}, y_{2}\right), & v_{3}=v\left(x_{3}, y_{3}\right) .
\end{array}
$$

Then, we can find the relationship between nodal displacement symbols $u_{1}, u_{2}, u_{3}, v_{1}, v_{2}$, and $v_{3}$ and inner parameters $u_{0}, u_{x}, u_{y}, v_{0}, v_{x}$, and $v_{y}$; it is a linear translation matrix. By solving the associated equations (9), we can get the distribution of the displacement as follows:

$$
\begin{aligned}
& u=u_{1} L_{1}+u_{2} L_{2}+u_{3} L_{3}+\theta_{z 1}\left(\frac{a_{1}}{2} y+\frac{c_{1}}{4} y^{2}+\frac{b_{1}}{2} x y\right) \\
& +\theta_{z 2}\left(\frac{a_{2}}{2} y+\frac{c_{2}}{4} y^{2}+\frac{b_{2}}{2} x y\right) \\
& +\theta_{z 3}\left(\frac{a_{3}}{2} y+\frac{c_{3}}{4} y^{2}+\frac{b_{3}}{2} x y\right) \\
& +\frac{\theta_{z 1}}{4(2 A)}\left\{x ( y _ { 2 } - y _ { 3 } ) \left[2 x_{1} y_{1}\left(y_{3}-y_{2}\right)\right.\right. \\
& +x_{2}\left(y_{1}+y_{2}\right)\left(y_{1}-y_{3}\right) \\
& \left.+x_{3}\left(y_{1}+y_{3}\right)\left(y_{2}-y_{1}\right)\right] \\
& +y\left(x_{2}-x_{3}\right) \\
& \cdot\left[\left(x_{1}-x_{2}\right)\left(y_{1}-y_{3}\right)^{2}+\left(x_{3}-x_{1}\right)\left(y_{1}-y_{2}\right)^{2}\right] \\
& -\left[x_{1} x_{2} y_{3}\left(2 y_{1}-y_{2}\right)\left(y_{2}-y_{3}\right)\right. \\
& +x_{1} x_{3} y_{2}\left(y_{3}-2 y_{1}\right)\left(y_{2}-y_{3}\right) \\
& +x_{2}^{2} y_{1} y_{3}\left(y_{3}-y_{1}\right)+x_{3}^{2} y_{1} y_{2}\left(y_{2}-y_{1}\right) \\
& +x_{2} x_{3} y_{1}\left[\left(y_{1}+y_{2}+y_{3}\right)\left(y_{2}+y_{3}\right)\right. \\
& \left.\left.\left.-6 y_{2} y_{3}\right]\right]\right\} \\
& +\frac{\theta_{z 2}}{4(2 A)}\left\{x ( y _ { 3 } - y _ { 1 } ) \left[2 x_{2} y_{2}\left(y_{1}-y_{3}\right)\right.\right. \\
& +x_{3}\left(y_{2}+y_{3}\right)\left(y_{2}-y_{1}\right) \\
& \left.+x_{1}\left(y_{2}+y_{1}\right)\left(y_{3}-y_{2}\right)\right]
\end{aligned}
$$




$$
\begin{aligned}
& +y\left(x_{3}-x_{1}\right) \\
& \cdot\left[\left(x_{2}-x_{3}\right)\left(y_{2}-y_{1}\right)^{2}+\left(x_{1}-x_{2}\right)\left(y_{2}-y_{3}\right)^{2}\right] \\
& -\left[x_{2} x_{3} y_{1}\left(2 y_{2}-y_{3}\right)\left(y_{3}-y_{1}\right)\right. \\
& +x_{1} x_{2} y_{3}\left(y_{1}-2 y_{2}\right)\left(y_{3}-y_{1}\right) \\
& +x_{3}^{2} y_{2} y_{1}\left(y_{1}-y_{2}\right)+x_{1}^{2} y_{2} y_{3}\left(y_{3}-y_{2}\right) \\
& +x_{3} x_{1} y_{2}\left[\left(y_{1}+y_{2}+y_{3}\right)\left(y_{1}+y_{3}\right)\right. \\
& \left.\left.\left.-6 y_{1} y_{3}\right]\right]\right\} \\
& +\frac{\theta_{z 3}}{4(2 A)}\left\{x ( y _ { 1 } - y _ { 2 } ) \left[2 x_{3} y_{3}\left(y_{2}-y_{1}\right)\right.\right. \\
& +x_{1}\left(y_{3}+y_{1}\right)\left(y_{3}-y_{2}\right) \\
& \left.+x_{2}\left(y_{3}+y_{2}\right)\left(y_{1}-y_{3}\right)\right] \\
& +y\left(x_{1}-x_{2}\right) \\
& \cdot\left[\left(x_{3}-x_{1}\right)\left(y_{3}-y_{2}\right)^{2}+\left(x_{2}-x_{3}\right)\left(y_{3}-y_{1}\right)^{2}\right] \\
& -\left[x_{3} x_{1} y_{2}\left(2 y_{3}-y_{1}\right)\left(y_{1}-y_{2}\right)\right. \\
& +x_{3} x_{2} y_{1}\left(y_{2}-2 y_{3}\right)\left(y_{1}-y_{2}\right) \\
& +x_{1}^{2} y_{3} y_{2}\left(y_{2}-y_{3}\right)+x_{2}^{2} y_{3} y_{1}\left(y_{1}-y_{3}\right) \\
& +x_{2} x_{1} y_{3}\left[\left(y_{1}+y_{2}+y_{3}\right)\left(y_{1}+y_{2}\right)\right. \\
& \left.\left.\left.-6 y_{1} y_{2}\right]\right]\right\} \text {, } \\
& v=v_{1} L_{1}+v_{2} L_{2}+v_{3} L_{3}+\theta_{z 1}\left(\frac{a_{1}}{2} x+\frac{b_{1}}{4} x^{2}+\frac{c_{1}}{2} x y\right) \\
& -\theta_{z 2}\left(\frac{a_{2}}{2} x+\frac{b_{2}}{4} x^{2}+\frac{c_{2}}{2} x y\right) \\
& -\theta_{z 3}\left(\frac{a_{3}}{2} x+\frac{b_{3}}{4} x^{2}+\frac{c_{3}}{2} x y\right) \\
& +\frac{\theta_{z 1}}{4(2 A)}\left\{-y\left(x_{2}-x_{3}\right)\left[2 x_{1} y_{1}\left(x_{3}-x_{2}\right)\right.\right. \\
& +y_{2}\left(x_{1}+x_{2}\right)\left(x_{1}-x_{3}\right) \\
& \left.+y_{3}\left(x_{1}+x_{3}\right)\left(x_{2}-x_{1}\right)\right] \\
& -x\left(y_{2}-y_{3}\right) \\
& \cdot\left[\left(y_{1}-y_{2}\right)\left(x_{1}-x_{3}\right)^{2}+\left(y_{3}-y_{1}\right)\left(x_{1}-x_{2}\right)^{2}\right] \\
& +\left[y_{1} y_{2} x_{3}\left(2 x_{1}-x_{2}\right)\left(x_{2}-x_{3}\right)\right. \\
& +y_{1} y_{3} x_{2}\left(x_{3}-2 x_{1}\right)\left(x_{2}-x_{3}\right) \\
& +y_{2}^{2} x_{1} x_{3}\left(x_{3}-x_{1}\right)+y_{3}^{2} x_{1} x_{2}\left(x_{2}-x_{1}\right) \\
& \left.\left.+y_{2} y_{3} x_{1}\left[\left(x_{1}+x_{2}+x_{3}\right)\left(x_{2}+x_{3}\right)-6 x_{2} x_{3}\right]\right]\right\}
\end{aligned}
$$

$$
\begin{aligned}
& +\frac{\theta_{z 2}}{4(2 A)}\left\{-y\left(x_{3}-x_{1}\right)\left[2 y_{2} x_{2}\left(x_{1}-x_{3}\right)\right.\right. \\
& +y_{3}\left(x_{2}+x_{3}\right)\left(x_{2}-x_{1}\right) \\
& \left.+y_{1}\left(x_{2}+x_{1}\right)\left(x_{3}-x_{2}\right)\right] \\
& -x\left(y_{3}-y_{1}\right) \\
& \cdot\left[\left(y_{2}-y_{3}\right)\left(x_{2}-x_{1}\right)^{2}+\left(y_{1}-y_{2}\right)\left(x_{2}-x_{3}\right)^{2}\right] \\
& +\left[y_{2} y_{3} x_{1}\left(2 x_{2}-x_{3}\right)\left(x_{3}-x_{1}\right)\right. \\
& +y_{1} y_{2} x_{3}\left(x_{1}-2 x_{2}\right)\left(x_{3}-x_{1}\right) \\
& +y_{3}^{2} x_{2} x_{1}\left(x_{1}-x_{2}\right)+y_{1}^{2} x_{2} x_{3}\left(x_{3}-x_{2}\right) \\
& \left.\left.+y_{3} y_{1} x_{2}\left[\left(x_{1}+x_{2}+x_{3}\right)\left(x_{1}+x_{3}\right)-6 x_{1} x_{3}\right]\right]\right\} \\
& +\frac{\theta_{z 3}}{4(2 A)}\left\{-y\left(x_{1}-x_{2}\right)\left[2 y_{3} x_{3}\left(x_{2}-x_{1}\right)\right.\right. \\
& +y_{1}\left(x_{3}+x_{1}\right)\left(x_{3}-x_{2}\right) \\
& \left.+y_{2}\left(x_{3}+x_{2}\right)\left(x_{1}-x_{3}\right)\right] \\
& -x\left(y_{1}-y_{2}\right) \\
& \cdot\left[\left(y_{3}-y_{1}\right)\left(x_{3}-x_{2}\right)^{2}+\left(y_{2}-y_{3}\right)\left(x_{3}-x_{1}\right)^{2}\right] \\
& +\left[y_{3} y_{1} x_{2}\left(2 x_{3}-x_{1}\right)\left(x_{1}-x_{2}\right)\right. \\
& +y_{3} y_{2} x_{1}\left(x_{2}-2 x_{3}\right)\left(x_{1}-x_{2}\right) \\
& +y_{1}^{2} x_{3} x_{2}\left(x_{2}-x_{3}\right)+y_{2}^{2} x_{3} x_{1}\left(x_{1}-x_{3}\right) \\
& \left.\left.+y_{2} y_{1} x_{3}\left[\left(x_{1}+x_{2}+x_{3}\right)\left(x_{1}+x_{2}\right)-6 x_{1} x_{2}\right]\right]\right\} \text {. }
\end{aligned}
$$

It can be proved that the assumed displacement is conforming.

2.3. The Stiffness Matrix of the Plane Element TR3 with RDOF. From (10), taking into account the definition of the strain field, we can get the strain matrix about the nodal displacement. It can be denoted as

$$
\begin{aligned}
& {[B]=\left[\left[B_{1}\right]\left[B_{2}\right]\left[B_{3}\right]\right] \text {, }} \\
& {\left[B_{1}\right]=\left[\begin{array}{ccc}
\frac{b_{1}}{2 A} & 0 & \frac{b_{1}\left(2 y-y_{1}-b_{x}\right)}{4} \\
0 & \frac{c_{1}}{2 A} & \frac{-c_{1}\left(2 x-x_{1}-b_{y}\right)}{4} \\
\frac{c_{1}}{2 A} & \frac{b_{1}}{2 A} & \frac{\left(x_{1} b_{1}+x_{2} b_{3}+x_{3} b_{2}\right)}{4}
\end{array}\right],}
\end{aligned}
$$




$$
\begin{aligned}
& {\left[B_{2}\right]=\left[\begin{array}{ccc}
\frac{b_{2}}{2 A} & 0 & \frac{b_{2}\left(2 y-y_{2}-b_{x}\right)}{4} \\
0 & \frac{c_{2}}{2 A} & \frac{-c_{2}\left(2 x-x_{2}-b_{y}\right)}{4} \\
\frac{c_{2}}{2 A} & \frac{b_{2}}{2 A} & \frac{\left(x_{1} b_{3}+x_{2} b_{2}+x_{3} b_{2}\right)}{4}
\end{array}\right],} \\
& {\left[B_{3}\right]=\left[\begin{array}{ccc}
\frac{b_{3}}{2 A} & 0 & \frac{b_{3}\left(2 y-y_{3}-b_{x}\right)}{4} \\
0 & \frac{c_{3}}{2 A} & \frac{-c_{3}\left(2 x-x_{3}-b_{y}\right)}{4} \\
\frac{c_{3}}{2 A} & \frac{b_{3}}{2 A} & \frac{\left(x_{1} b_{2}+x_{2} b_{1}+x_{3} b_{3}\right)}{4}
\end{array}\right],}
\end{aligned}
$$

in which

$$
\begin{aligned}
& b_{x}=\frac{\left(x_{1} y_{1} b_{1}+x_{2} y_{2} b_{2}+x_{3} y_{3} b_{3}\right)}{2 A}, \\
& b_{y}=\frac{\left(x_{1} y_{1} c_{1}+x_{2} y_{2} c_{2}+x_{3} y_{3} c_{3}\right)}{2 A} .
\end{aligned}
$$

Then, the stiffness matrix can be obtained:

$$
[K]=\iint_{A}[B]^{T}[D][B] d A
$$

where

$$
[D]=\frac{E}{1-\mu^{2}}\left[\begin{array}{ccc}
1 & \mu & 0 \\
\mu & 1 & 0 \\
0 & 0 & \frac{1-\mu}{2}
\end{array}\right] \text {. }
$$

2.4. The Stiffness Matrix Using the Explicit Integral Formulae. The strain matrix of the triangular plane element TR3 with RDOF can be presented in the natural coordinates of the triangular element. The stress trial functions contain the variables $x$ and $y$, which can be written as

$$
\begin{aligned}
& x=x_{1} L_{1}+x_{2} L_{2}+x_{3} L_{3}, \\
& y=y_{1} L_{1}+y_{2} L_{2}+y_{3} L_{3} .
\end{aligned}
$$

Then, the matrix $[K]$ can be expressed in the natural coordinates $L_{1}, L_{2}$, and $L_{3}$. To the integral formula of the natural coordinates in the triangular element, we have

$$
\begin{gathered}
\iint_{A} L_{1}^{a} L_{2}^{b} L_{3}^{c} d x d y=\frac{a ! b ! c !}{(a+b+c+2) !} 2 A, \\
\int_{l} L_{1}^{a} L_{2}^{b} d s=\frac{a ! b !}{(a+b+1) !} l_{12},
\end{gathered}
$$

where $A$ is the area of the triangular element. Utilizing the explicit integral formulae of (16) in the triangular element, the explicit formula of the proposed elements in this paper can be obtained.

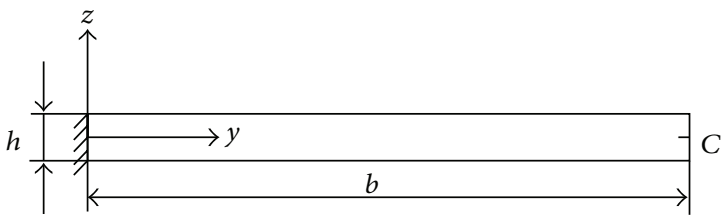

Figure 1: Cantilever beam subjected to force/moment.
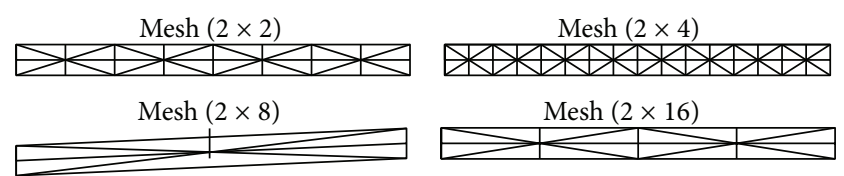

Figure 2: Schemes of the mesh.

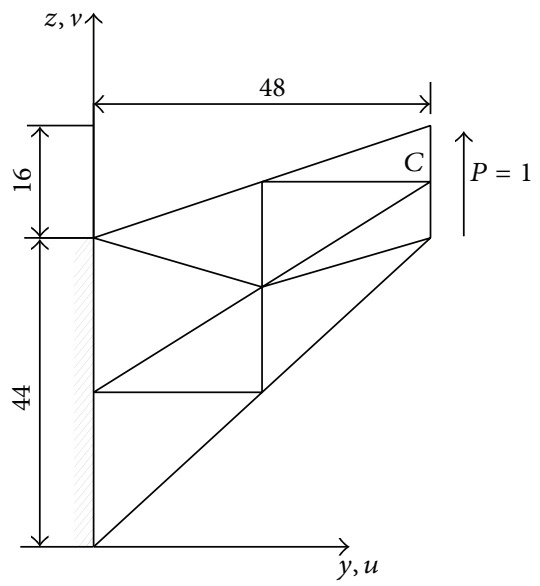

Figure 3: Cook's skew shell.

TABLE 1: Deflection $V_{C z} / \mathrm{m}$ of the cantilever beam subjected to $M_{x}$.

\begin{tabular}{lcccc}
\hline \multirow{2}{*}{ Element } & \multicolumn{5}{c}{ Mesh } \\
& $2 \times 2$ & $2 \times 4$ & $2 \times 8$ & $2 \times 16$ \\
\hline CST & 0.0128 & 0.0489 & 0.1654 & 0.4058 \\
GT9 & 0.1045 & 0.3156 & 0.6371 & 0.8510 \\
GT9M & 0.1049 & 0.3191 & 0.6504 & 0.8692 \\
TR3 & 0.9906 & 0.9903 & 0.9911 & 0.9961 \\
\hline
\end{tabular}

\section{Benchmark of the Proposed Element TR3}

3.1. Cantilever Beam. As shown in Figure 1, a slender cantilever beam has the length $b$ of $32 \mathrm{~m}$, the height $h$ of $2 \mathrm{~m}$, and the thickness $t$ of $1 \mathrm{~m}$. It is made of the isotropy material, which has the material parameters $E=768 \mathrm{~Pa}, \mu=0.25$. Figure 2 shows four schemes of the mesh to the proposed cantilever beam.

The load is an in-plane moment $M_{x}=1 \mathrm{~N} \cdot \mathrm{m}$ on the end side $C$. Table 1 gives the results of the displacement $V_{C z}$ obtained by the proposed element TR3. Comparing with other elements, TR3 can give higher precise results.

3.2. Cook's Skew Beam. As showed in Figure 3, the Cook's skew beam [10] is studied. The thickness $t$ of the shell is $1 \mathrm{~m}$. 
TABLE 2: Deflections $(\mathrm{m})$ of the central point $C$ in different mesh scheme.

\begin{tabular}{lcccccc}
\hline \multirow{2}{*}{ Element } & \multicolumn{5}{c}{ Mesh } \\
& $2 \times 2$ & $4 \times 4$ & $8 \times 8$ & $16 \times 16$ & $32 \times 32$ & $64 \times 64$ \\
\hline CST & 11.99 & 18.28 & 22.02 & 23.41 & $/$ & $/$ \\
GT9 & 20.08 & 22.71 & 23.61 & 23.87 & 23.94 & 23.96 \\
GT9M & 20.36 & 22.80 & 23.63 & 23.88 & 23.94 & 23.96 \\
TR3 & 19.66 & 22.46 & 23.47 & 23.81 & 23.92 & 23.95 \\
\hline
\end{tabular}

It is also made of the isotropy, whose material parameters $E=$ $1 \mathrm{~Pa}, \mu=0.3333$, and is subjected to the uniformly distributed load which has the sum of $P=1 \mathrm{~N}$. Table 2 gives the deflection of the central point $C$ in different mesh scheme.

\section{Conclusion}

This paper present a new type of plane element with RDOF: the assumptions of the rotational displacement and the displacement are proved to be useful. The accuracy and the efficiency of the proposed element model TR3 are shown in the benchmark problems.

\section{Conflict of Interests}

The authors declare that there is no conflict of interests regarding the publication of this paper.

\section{Acknowledgments}

This project is supported by the National Natural Science Foundation of China (no. 11272340) and the National Basic Research Programs of China (no. 2010CB731503).

\section{References}

[1] O. C. Zienkiewicz and R. L. Taylor, The Finite Element Method for Solid and Structural Mechanics, Elsevier ButterworthHeinnemann, Oxford, UK, 6th edition, 2005.

[2] Y. Q. Long, S. Cen, and Z. F. Long, Advanced Finite Element Method in Structural Engineering, Springer, Berlin, Germany, 2009.

[3] R. W. Clough, "The finite element method in plane stress analysis," in Proceedings of the 2nd ASCE Conference on Electronic Computation, vol. 9, pp. 8-9, Pittsburgh, Pa, USA, 1960.

[4] D. O. Mervyn and W. B. Terrence, "A simple flat shell element revisited," International Journal for Numerical Methods in Engineering, vol. 11, pp. 1041-1043, 1979.

[5] G. A. Mohr, "Finite element formulation by nested interpolations: application to the drilling freedom problem," Computers \& Structures, vol. 15, no. 2, pp. 185-190, 1982.

[6] D. J. Allman, "A compatible triangular element including vertex rotations for plane elasticity analysis," Computers and Structures, vol. 19, no. 1-2, pp. 1-8, 1984.

[7] R. D. Cook, "Modified formulations for nine-D.O.F. plane triangles that include vertex rotations," International Journal for Numerical Methods in Engineering, vol. 31, no. 5, pp. 825-835, 1991.
[8] R. D. Cook, D. S. Malkus, and M. E. Plesha, Concepts and Applications of Finite Element Analysis, John Wiley \& Sons, New York, NY, USA, 1989.

[9] R. H. MacNeal and R. L. Harder, "A refined four-noded membrane element with rotational degrees of freedom," Computers and Structures, vol. 28, no. 1, pp. 75-84, 1988.

[10] A. Ibrahimbegovic and E. L. Wilson, "A unified formulation for triangular and quadrilateral flat shell finite elements with six nodal degrees of freedom," Communications in Applied Numerical Methods, vol. 7, no. 1, pp. 1-9, 1991.

[11] S. Cen, Y.-Q. Long, Z.-H. Yao, and S.-P. Chiew, "Application of the quadrilateral area co-ordinate method: a new element for Mindlin-Reissner plate," International Journal for Numerical Methods in Engineering, vol. 66, no. 1, pp. 1-45, 2006.

[12] X.-R. Fu, Y.-Q. Long, M.-W. Yuan, and S. Cen, "A generalized conforming plane element with internal parameters based on analytical trial functions," Engineering Mechanics, vol. 23, no. 1, pp. 1-5, 2006 (Chinese).

[13] X. R. Fu, S. Cen, C. F. Li, and X. M. Chen, "Analytical trial function method for development of new 8-node plane element based on the variational principle containing airy stress function," Engineering Computations, vol. 27, no. 4, pp. 442-463, 2010.

[14] S. Cen, X.-R. Fu, and M.-J. Zhou, "8- and 12-node plane hybrid stress-function elements immune to severely distorted mesh containing elements with concave shapes," Computer Methods in Applied Mechanics and Engineering, vol. 200, no. 29-32, pp. 2321-2336, 2011.

[15] S. Cen, M.-J. Zhou, and X.-R. Fu, "A 4-node hybrid stressfunction (HS-F) plane element with drilling degrees of freedom less sensitive to severe mesh distortions," Computers and Structures, vol. 89, no. 5-6, pp. 517-528, 2011.

[16] S. Cen, X. R. Fu, G. Zhou, M. J. Zhou, and C. F. Li, "Shape-free finite element method: the plane hybrid stress-function (HSF) element method for anisotropic materials," Science China: Physics, Mechanics and Astronomy, vol. 54, no. 4, pp. 653-665, 2011.

[17] S. Cen, G.-H. Zhou, and X.-R. Fu, "A shape-free 8-node plane element unsymmetric analytical trial function method," International Journal for Numerical Methods in Engineering, vol. 91, no. 2, pp. 158-185, 2012.

[18] S. Cen, Y. Q. Long, Z. H. Yao, and S. P. Chiew, "Application of the quadrilateral area co-ordinate method: a new element for Mindlin-Reissner plate," International Journal for Numerical Methods in Engineering, vol. 66, no. 1, pp. 1-45, 2006.

[19] S. Cen, A.-K. Soh, Y.-Q. Long, and Z.-H. Yao, "A new 4node quadrilateral FE model with variable electrical degrees of freedom for the analysis of piezoelectric laminated composite plates," Composite Structures, vol. 58, no. 4, pp. 583-599, 2002.

[20] X.-M. Chen, S. Cen, Y.-Q. Long, and Z.-H. Yao, "Membrane elements insensitive to distortion using the quadrilateral area coordinate method," Computers \& Structures, vol. 82, no. 1, pp. 35-54, 2004.

[21] T. H. H. Pian, "Derivation of element stiffness matrices by assumed stress distributions," AIAA Journal, vol. 2, no. 7, pp. 1333-1336, 1964.

[22] X.-R. Fu, M.-W. Yuan, S. Cen, and G. Tian, "Characteristic equation solution strategy for deriving fundamental analytical solutions of 3D isotropic elasticity," Applied Mathematics and Mechanics, vol. 33, no. 10, pp. 1253-1264, 2012.

[23] S. Cen, X. Fu, Y. Long, H. Li, and Z. Yao, "Application of the quadrilateral area coordinate method: a new element for 
laminated composite plate bending problems," Acta Mechanica Sinica, vol. 23, no. 5, pp. 561-575, 2007.

[24] W.-J. Wang, G. Tian, X.-R. Fu, and Y. Zhao, "A strategy for formulating the fundamental analytical solutions by solving the characteristic equations of plane problems with anisotropic materials," Journal of Engineering Mechanics, vol. 29, no. 9, pp. 11-16, 2012 (Chinese).

[25] X.-R. Fu, L.-N. Ge, G. Tian, and M.-W. Yuan, "Study on the explicit formula of the triangular flat shell element based on the analytical trial functions for anisotropy material," Mathematical Problems in Engineering, vol. 2013, Article ID 486453, 9 pages, 2013.

[26] G. Tian, X.-R. Fu, M.-W. Yuan, and M.-Y. Song, "The characteristic solutions to the V-notch plane problem of anisotropy and the associated finite element method," Mathematical Problems in Engineering, vol. 2013, Article ID 593640, 11 pages, 2013. 


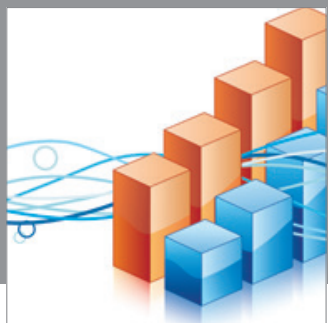

Advances in

Operations Research

mansans

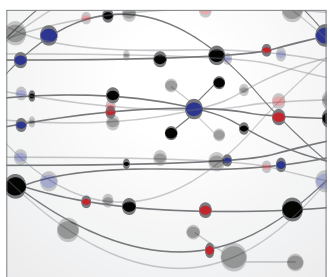

The Scientific World Journal
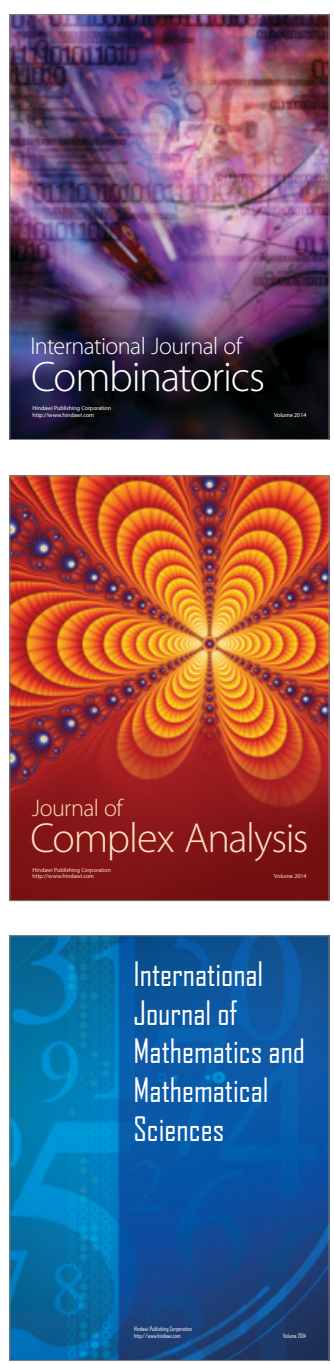
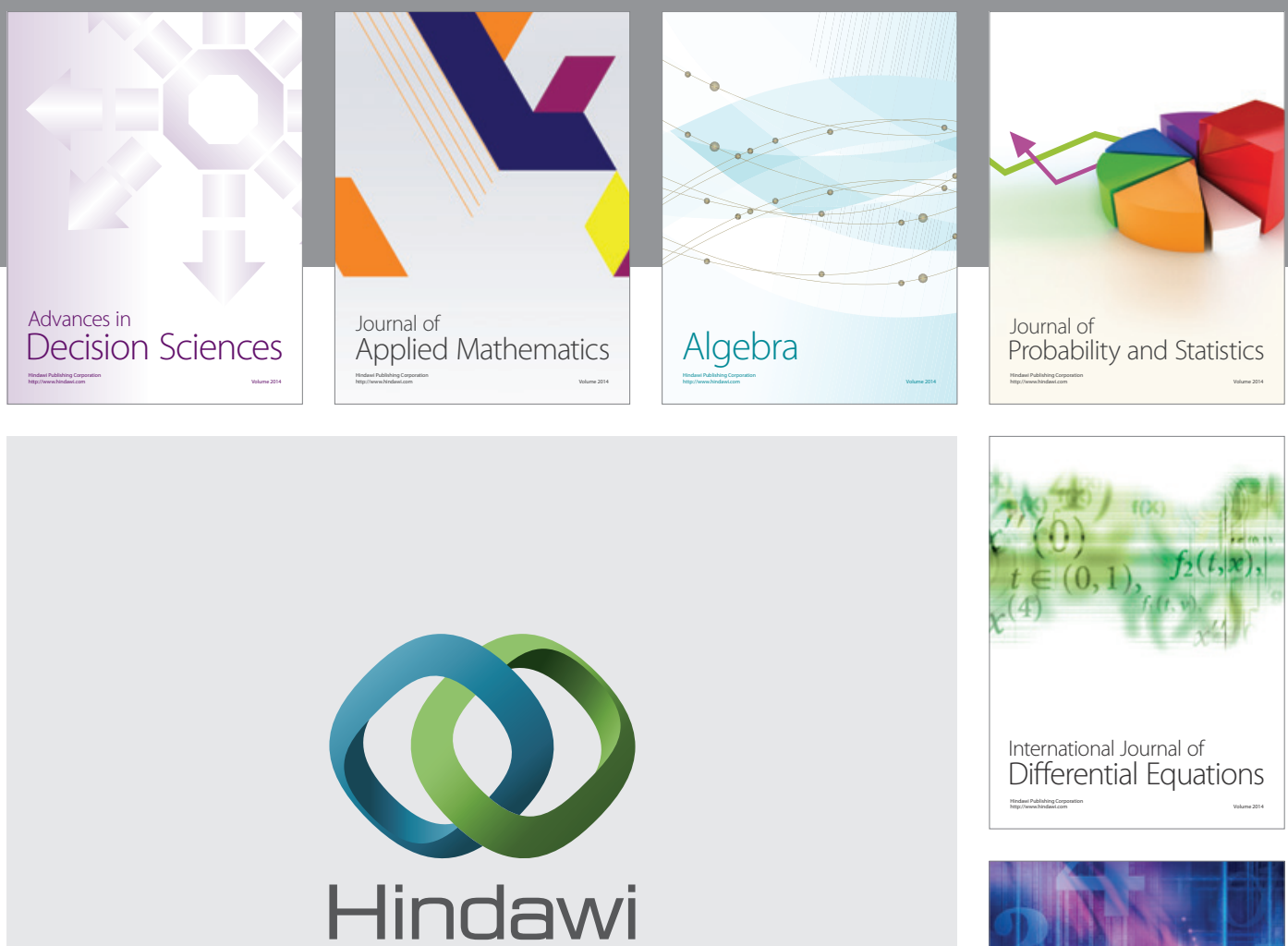

Submit your manuscripts at http://www.hindawi.com
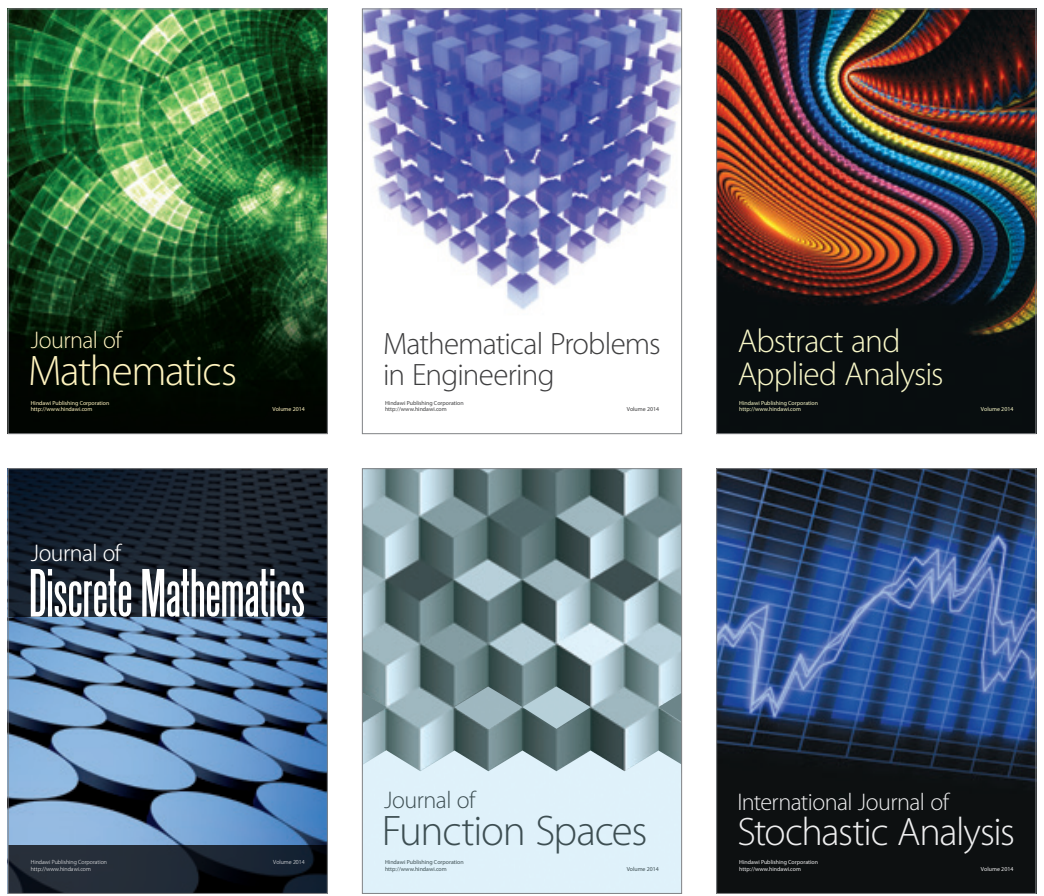

Journal of

Function Spaces

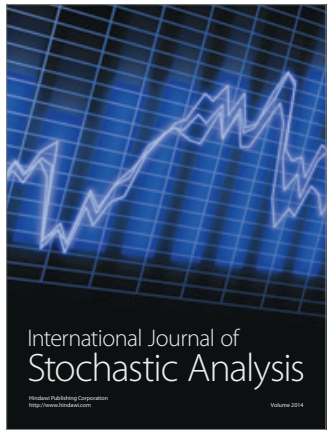

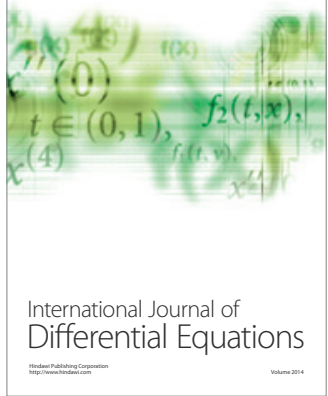
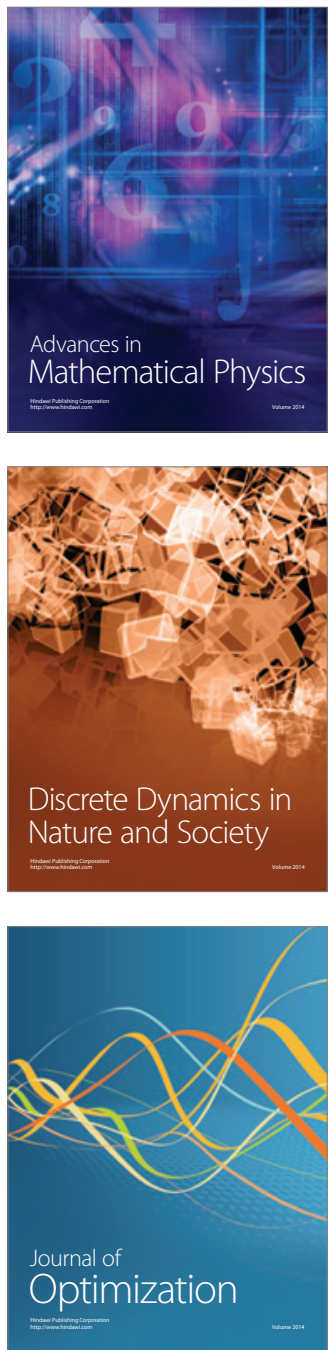